Research Article

\title{
Influence of Bachelor of Education Teacher Trainees' Information Searching Ability on Utilization of E-resources At University of Nairobi Kenya
}

\author{
John Njoroge Kanori ${ }^{1}$, Odundo Paul Amollo ${ }^{2}$, Hellen Nasimiyuh Inyega ${ }^{3}$ \\ 1,2,3 Department of Educational Communication and Technology, School of Education \\ University of Nairobi, KENYA
}

\begin{abstract}
Utilization of electronic resources is a reading culture that benefits bachelor of education teacher trainees (BEDTTs) by directly exposing the learners to up-to-date and vast subject content in motivating multimedia presentations. The BEDTTs benefits from utilizing e-resources by retrieving information faster than print resources. The BEDTTs use the time saved to do more academic work. The study examined the relationship between BEDTTs' information searching ability and utilization of e-resources. The objective of the study was to establish the relationship between BEDTTs' searching ability and utilization of e-resources. The study adopted descriptive research design. Stratified random sampling was used to draw a sample of 370 BDTTs. Purposeful sampling method was used to obtain 30 staff who interact with BEDTTs either in class, library or administratively. Validity was ascertained using experts from the department of educational communication. The instrument demonstrated high internal consistency (>.90) using test-retest method. Validity was ascertained using Cronbachs' alpha coefficient. Data was collected using questionnaires, interview guides and document analysis guide. Data was analyzed using descriptive and inferential statistical techniques. The findings revealed a significant relationship between BEDTTs' information searching ability and utilization of e-resources. The findings recommended implementation of embedded information skills lessons from first year to fourth year, joint IL curriculum mapping between lecturers, library staff and information skills librarians, intense marketing of the availability of eresources to the University community and teaching BEDTTs a wide range of searching techniques. The study recommended a replication of a longitudinal study on influence of information literacy instruction on utilization of eresources.
\end{abstract}

Keywords: Influence, Teacher Trainees, Information, Searching, Ability, Utilization, E-resources

\section{Introduction}

Utilization of electronic resources in class is an information culture that benefits BEDTTs by stimulating learning experiences for the learners. Shittu, Kareem, Obielodan, and Fakomogbon (2017) asserted that e-resources inject innovation in teaching and learning in addition to speeding up discovery and creation of new enquiries in education. The lecturers' role of integrating e-resources in class work expose the BEDTTs to rich learning experiences. Additionally, Khan (2016) averred that e-resources can be accessed remotely. This means that geographical barriers such as distance and time have been overcome. The BEDTTs can access e-resources in the library or at home to prepare class notes, complete assignments or set interactive physical education (PE) exercises. Schugar, Smith and Schugar (2013) posits that ebooks are interactive and enhance students' learning outcomes. Mishrah and Koehler (2006) averred that digital technology allow teachers to make multimedia presentations of subject content more interesting, entertaining and interactive. E-resources appeal to a wide audience because of engaging several BEDTTs with different learning styles. Okello-Obura and Magara (2008) agreed the advantages of eresources include ease of use, speed, access to digital resources outside the library and access to multiple files.

However, to utilize e-resources effectively, PSTs require literate abilities of online searching techniques, evaluating and referencing of e-resources. Fallon and Breen (2012) observed that academic libraries are involved with providing information literacy (IL) and e-resources. Ukachi (2015) noted positive correlation between undergraduates' information literate abilities and utilization of e-resources. This implies that teaching BEDTTs a wide range of online searching techniques would empower the learners with skills of utilizing e-resources. Kovalik, Jensen, Schloman and Tipton (2010) agreed that ILs pedagogy is vital because not only does it empower BEDTTs with IL abilities but also empower the BEDTTs with skills of transferring the abilities to students. When BEDTTs influence students to utilize e-resources after joining the teaching career, this action would promote utilization of e-resources.

\section{Literature Review}

\section{Concept of information Literacy}

The Association of College and Research Libraries (ACRL) (2016) define IL as the set of integrated abilities of discovering and utilizing information ethically to generate knowledge and participate in scholarly communication. The study believes that the instruction librarian has the obligation to empower BEDTTs with IL abilities of searching various edatabases through applying various searching techniques for better results. Lwoga (2014) observed the necessity for undergraduates to acquire IL abilities to control course-related 
activities in addition to developing lifelong skills. This implies that information literate BEDTTs are able to search for relevant information independently. Fister (2013) asserted that employers stress the need for IL graduates who can think, communicate and solve problems. This implies that IL is one of acknowledged life-long skills which graduates are expected to acquire while at the university and apply the skills in managerial or office work after graduating.

Duke and Ward (2009) confirmed that education faculties are aware that IL is important in shaping students' lives. The study stress the need for BEDTTs to acquire IL abilities which are vital not only in academic circles but also in everyday life. Furthermore information literate BEDTTs have the capacity to impart the skills to students after joining the teaching career. The BEDTTs who are information literate utilize all eresources recommended by academic staff and instruction librarians. Mardhusudhan (2010) confirmed that IL abilities are necessary for one to utilize e-resources and added that librarians impart IL skills through inducting users on the use of these sources. Teaching BEDTTs searching skills would not only prepare them for a successful academic career but also empower them with life-long skills that are necessary in professional and private life.

\section{Information searching techniques}

Medical Library Africa (2017) asserted that searching techniques refer to use of search

terms to look for information from search tools such as e databases, search engines or portals. Use of searching techniques empower information searchers with the ability to broaden or narrow the search to achieve relevant search results. The BEDTTs need instruction on how to construct successful search techniques. The various searching techniques which BEDTTs should be conversant with include Boolean operator, keyword, phrase, wildcard and truncation searching techniques. Lwoga (2014) affirmed that keyword searching is the use of a word specified by the user in an online database. Starret (1994) revealed that keyword search is the basic search one can do but lamented that one gets too many hits that are not relevant. For instance, a search on Cholera will yield many hits on cholera. However, one can narrow the search by adding search words picked from the title, for instance Cholera Kenya which narrows the search and yields less but more relevant search results because the topic focuses on one geographical area, that is, Cholera in Kenya. Another searching technique which EDTTs ought to be taught is the Boolean operator. Porter (2011) observed that Boolean Language is a system relying on Boolean operators to retrieve relevant articles. Boolean operators are words (AND, OR, or $N O T$ ) used as conjunctions to combine or exclude keywords in a search resulting in more relevant documents and helps to retrieve information quickly (Alliant Libraries, 2017). Use of $A N D$ operator narrows the search for instance, Mosquito AND Malaria search retrieves documents that discuss both mosquito and malaria. Use of $O R$ operator broadens the search. For instance, Mosquito $O R$ Malaria increases the number of documents retrieved that discusses either Malaria or mosquito. The operator NOT widens the search and yields better results. Mosquito NOT Malaria retrieves document that discuss parasites called mosquito but exclude malaria.

Porter (2011) confirmed that undergraduate students use natural language but they expended little time in developing search terms to increase precision of their search. Phrase searching on the other hand instructs search tools to search only words that occur side by side within the quotes, for instance "Learning and teaching" or "early childhood education" or "lesson plan". The search retrieves only articles with the phrases appearing within the quote but omits articles with separate words like lesson, and plan because they are not relevant. The technique narrows the search so as to yield relevant results. Wildcard is another searching technique which refer to symbols used in searching information. Wildcard is used where the one searching the information is not sure of the spelling of the word due to variations in American and English words. EbscoHOST (2017) agreed that wildcard is commonly represented by a question mark ? The ? wildcard is used to replace an unknown letter in a word where the user is not sure of the spelling, for instance $l a b o$ ? $r$ or endeavo? $r$. The search retrieves all citations containing labor or labour or endeavor and endeavour respectively. The study emphasizes the need for BEDTTs to be conversant with wildcard to retrieve articles on concepts which have slightly different spellings.

Truncation searching technique is the other technique which the BEDTTs ought to be conversant with. Truncation searching denotes the use of an asterik* to broaden the search. Medical Library Africa (2017) observed that use of truncation at the root of a word instructs the search tool to search all word variations for instance Child* or Comput* yields citations with child, children and childhood and computer and computing respectively. The search yields all articles that are related to the word with the asterisk.

\section{Bachelor of education trainees' searching abilities and utilization of e-resources}

Sithole, Chisita and Jagero (2014) revealed that access and use of e-journals is covered in the IL course at the Africa University. Southeastern Louisiana University (2010) confirmed that e-databases and searching websites are some of the topics incorporated in the Introduction to Information Research course offered to undergraduates. In the same vein, Kovalik, Jensen, Schloman and Tipton (2010) survey on teacher education faculties in USA revealed that BEDTTs are instructed on internet searching, utilizing e-resources and searching techniques. Academic institutions train students on a range of searching skills because utilizing e-resources require one to be conversant with various techniques. However, the following literature review indicate that undergraduate students hardly utilize e-resources to perform teaching, learning and research related tasks.

Oparah and Faloye (2015) observed that effective utilization of e-resources in institutions of higher learning is impeded by 
poor information retrieval skills, poor IL and poor evaluation skills among other factors. Omosekejimi, Ehworo and Ogo (2015) agreed that many students in academic institutions don't utilize e-resources availed to them by their respective universities due to lack of awareness or lack of skills to navigate the e-resources. Nyamboga (2014) confirmed that undergraduate students face challenges of accessing eresources due to lack of searching skills. In the same vein, Ekenna and Iyabo (2013) observed that undergraduate students lack requisite information retrieval skills and avoid to interact with e-resources. Similarly, Adeniran (2013) affirmed barriers on utilization of e-journals by undergraduates due to lack of awareness of the availability of e-resources and poor searching abilities.

However, other studies on utilization of e-resources revealed that undergraduates utilize e-resources. Dhanavandan, Esmail and Nagaranjan (2012) confirmed that (32\%) students use eresources once in a week, most of the faculties used eresources twice a week whereas $11.5 \%$ of the respondents rarely used e-resources. Toyo (2017) affirmed that information science students utilize e-resources satisfactorily because they are information literate.

\section{Statement of the problem}

The University of Nairobi (UoN) spends colossal amount of money annually to subscribe to a wide range of e-resources. The UoN also has an institutional repository that captures, preserves and provides access to digital resources created university community. (https://erepository.uonbi.ac.ke, 2017). The high quality, peer-reviewed e-resources are accessible to all anywhere, anytime through any e-device via remote access. The UoN Library System (UoNLS) and the School of Education (SoE) have installed information communication technologies (ICTs) comprising networked computers and WIFI. The BEDTTs are expected to utilize a wide range of eresources for academic work.

However, there have been complaints from information skills librarians (ISLs) and lecturers that BEDTTs are hardly inducted on the use of e-resources. This means that the BEDTTs are not conversant with a wide range of searching techniques and weakens the ability of the BEDTTs' to utilize e-resources. This situation is of concern because BEDTTs are not linked directly to current and vast amount of subject content that lead to improved subject performance. This might lead to BEDTTs scoring lower grades compared to undergraduates who utilize e-resources.

\section{Objective of the study}

The objective of this study was to establish the relationship between BEDTTs' searching ability and utilization of eresources

\section{Theoretical context}

The study was guided by Gagne's theory of instruction which was propounded in 1992. The theory was based on the information processing model. Burba (2013) asserted that
Gagne coined the term instructional design when researching and developing training materials for the US military in the 1960's. Kayvan, Kamran and Sauid (2011) agreed that Gagne's theory has provided valuable ideas to many trainers and teachers. The theory has been applied in the design of instructions for the military, leadership, healthcare and engineering. Driscoll (1994) breaks the theory into three components; taxonomy of learning outcomes, conditions of learning and nine events of instruction. The theory informs library staff and information skill librarians (ISLs) of the necessity to ensure that the ICT environment is conducive to learning by installing stable internet and adequate functional computers. Such excellent external conditions encourage the BEDTTs to learn without interruptions.

The last component, comprising the nine events of instruction which refer to actions of both teacher and students during the lesson, resonate well with the current study. The events are hierarchical in order to have successful instruction. The third event, 'stimulating recall of prior knowledge' for instance, would help the instructors to know the BEDTTs' IL level so as to customize the new content accordingly. The BEDTTs would be asked to give prior knowledge of using the online catalogue to locate a hard copy of a book. The BEDTTs have varying IL exposure in early childhood before nursery, during nursery, primary and high schools. The instructors can then classify the BEDTTs into respective IL levels and prepare appropriate new content that matches those levels. Additionally, the eighth event, assessing performance, is relevant because it informs IL instructors how to confirm whether the BEDTTs have acquired the skills of utilizing eresources. This could be achieved by administering CATs after every topic.

The theory could also be used in designing instructions for teaching BEDTTs psycho-motor skills in searching edatabases. The library staff, lecturers and ISLs could prepare a lesson plan, guided by the nine events. About 20 BEDTTs could take part in a hands-on lesson, conducted in a computer lab with 21 networked computers, with reliable internet. The ISL could take the BEDTTs through step by step process of using specific searching techniques such as phrase searching, projecting the steps on the screen for all to see and repeat. Computer technicians could be on the alert to assist the BEDTTs to keep pace with the ISL. To enhance retention, the BEDTTs could repeat the whole process another time. The ISL could cover Boolean operator, truncation, wildcard and keyword searching techniques allowing the BEDTTs to have hands-on experience.

\section{Research Methodology}

The study adopted descriptive design. The target population for this study included 3082 BEDTTs of UoN from second to fourth year enrolled in the 2016/2017 academic year, 10 librarians in Kenya Science Campus (KSC) library and CEES library Kikuyu, 66 lecturers, two information skills librarians (ISLs) and four administrators from the School of Education. The target population for the entire category of respondents 


\section{Odundo Paul Amollo et al / Influence of Bachelor of Education Teacher Trainees' Information Searching Ability on Utilization of E-resources At University of Nairobi Kenya}

was 3164. Stratified random sampling procedure was used to ensure each student participated in the study. The study adopted $12 \%$ of the total population of 3082 BEDTTs to arrive at a sample size of 370 . Purposive sampling was used to select three library staff from KSC Library and three library staff from CEES Library Kikuyu, two information skills librarians, 20 lecturers who teach BEDTTs different subjects and two administrators from the School of Education. The sample size for the study was 400 respondents. Data was collected using questionnaires, interview guides and document analysis guide. Five sets of questionnaires for BEDTTs, lecturers, library staff, ISLs and administrators were developed for collecting data. Another three sets of interview guides were developed to collect data from BEDTTs, ISLs and library staff. Content validity was ascertained using supervisors from the department of educational communication. For this study the reliability test yielded 0.92 Cronbach's coefficient alpha. Data was analyzed using descriptive and inferential statistics.

\section{Gender and Utilization of e-resources}

The study sought to establish whether utilization of eresources by BEDTTs was influenced by gender. The BEDTTs were asked to indicate participation in utilization of e-resources. The findings revealed that $142(79 \%)$ male PSTs and $106(73 \%)$ female BEDTTs utilize e-resources. The findings indicated that BEDTTs' utilization of e-resources did not vary by gender because, male and female utilized eresources almost equally at $142(79 \%)$ and $106(73 \%)$ respectively.

A chi square test was used to establish the relationship between the gender of the BEDTTs and utilization of eresources. The findings were presented in Table 1

Table 1: Test on bachelor of education trainees' utilization of e-resources by gender

\begin{tabular}{llll}
\hline & Value & Df & $\begin{array}{l}\text { Asymp. } \\
\text { Sig.(2-sided) }\end{array}$ \\
\hline $\begin{array}{l}\text { Pearson Chi- } \\
\text { Square }\end{array}$ & $1.730^{\mathrm{a}}$ & 1 & .188 \\
$\begin{array}{l}\text { Continuity } \\
\text { Correction b }\end{array}$ & 1.400 & 1 & .237 \\
$\begin{array}{l}\text { Likelihood Ratio } \\
\text { Fisher's Exact Test }\end{array}$ & 1.722 & 1 & .189 \\
$\begin{array}{l}\text { Linear-by-Linear } \\
\text { Association }\end{array}$ & 1.724 & 1 & .189 \\
N of Valid Cases & 324 & & \\
\hline
\end{tabular}

The findings presented in Table 1 indicated that there is no statistical significant association between BEDTTs' gender and utilization of $(p>0.05)$.This implied that utilization of eresources by BEDTTs is not influenced by gender. The findings indicated that both gender almost equally utilized eresources. The findings corroborates with Yusuf and Balogun (2011) findings which revealed that there were no significant differences between male and female pre-service teachers' competencies in the use of ICTs.

\section{Findings of the study}

Bachelor of education trainees' searching ability and utilization of e-resources

The study sought to determine the relationship between BEDTTs' searching ability and utilization of e-resources. The BEDTTs were asked to rate conversance with specific online searching techniques. The findings are presented in Figure 1

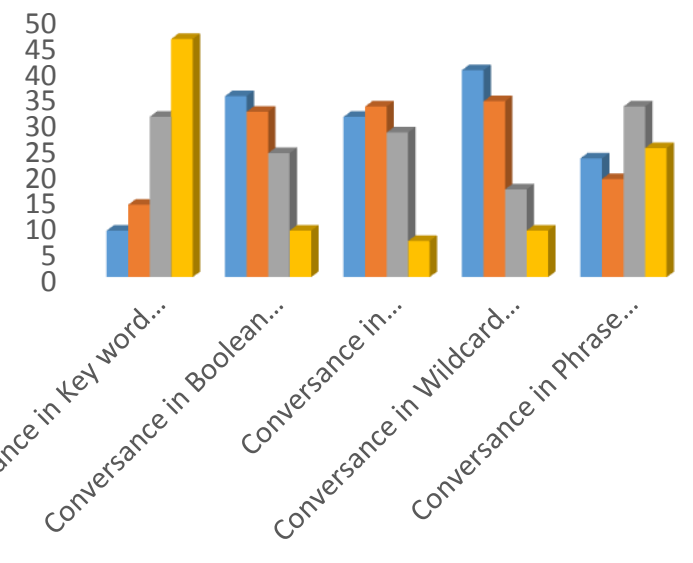

Figure 1: Bachelor of education trainees' conversance with searching techniques

The findings confirmed that $167(46 \%)$ BEDTTs rated conversance with keyword searching techniques, as excellent, while $113(31 \%)$ PSTs rated conversance with keyword searching, as good. Further findings indicated that 51(14\%) BEDTTs rated conversance with keyword searching, as average, whereas $32(9 \%)$ BEDTTs rated conversance with keyword searching, as poor. This meant that $280(77 \%)$ BEDTTs are good at picking keywords from a title and conduct a search. More still, the findings revealed that $32(9 \%)$ BEDTTs rated conversance with Boolean operator searching technique, as excellent, whereas $87(24 \%)$ BEDTTs rated conversance with Boolean operator searching, as good. Additionally, $117(34 \%)$ BEDTTs rated conversance with Boolean operator searching, as average, while 127(35\%) BEDTTs rated conversance with Boolean operator searching, as poor. Findings indicated that 244(69\%) BEDTTs were not comfortable when using Boolean operator technique.

Moreover, the findings indicated that 25(7\%) BEDTTs rated conversance with truncation searching technique, as excellent, $102(28 \%)$ BEDTTs rated conversance with truncation searching technique, as good, 120(33\%) PSTs rated conversance with truncation searching technique, as average, whereas $113(31 \%)$ BEDTTs rated conversance with truncation searching technique, as poor. Findings revealed that 233(64\%) BEDTTs are not familiar with using truncation technique, that is using an asterick* to broaden a search. Similarly, the findings affirmed that $32(9 \%)$ BEDTTs rated conversance with wildcard searching technique, as excellent, whereas $62(17 \%)$ BEDTTs rated conversance with wildcard searching technique, as good. More still, 124(34\%) BEDTTs rated 
conversance with wildcard searching technique, as average, while $146(40 \%)$ rated conversance with wildcard searching technique, as poor. This implied that 270(74\%) BEDTTs were not conversant with using a wildcard denoted by a question mark ( ?) to search words with varying spellings. Additionally, as average, whereas $84(23 \%)$ BEDTTs rated conversance with phrase searching technique, as poor. Findings revealed $211(58 \%)$ BEDTTs are good in searching information using phrases such as' information literacy' or 'lesson plan'

A large numbers of BEDTTs were rated to have poor searching techniques on Boolean operator 127(35\%), truncation $120(33 \%)$ and wildcard $146(40 \%)$. The findings corroborates with findings on staff's participation in teaching BEDTTs searching techniques. Findings indicated that $2(33 \%), 4(67 \%)$ and $5(83 \%)$ library staff rarely taught BEDTTs Boolean operator, truncation and wildcard respectively. This situation is of concern because the BEDTTs lack the necessary range of searching techniques that could enable them to search specific information sought, locate and utilize e-resources. The findings are line with the findings of research conducted by Mwantimwa (2017) which confirmed low use of e-resources by students in Mzumbe University due to low searching skills.

\section{Staff participation in teaching searching techniques}

The study sought to establish the participation of staff in teaching BEDTTs skills in searching techniques. The findings are presented in figure 2 .

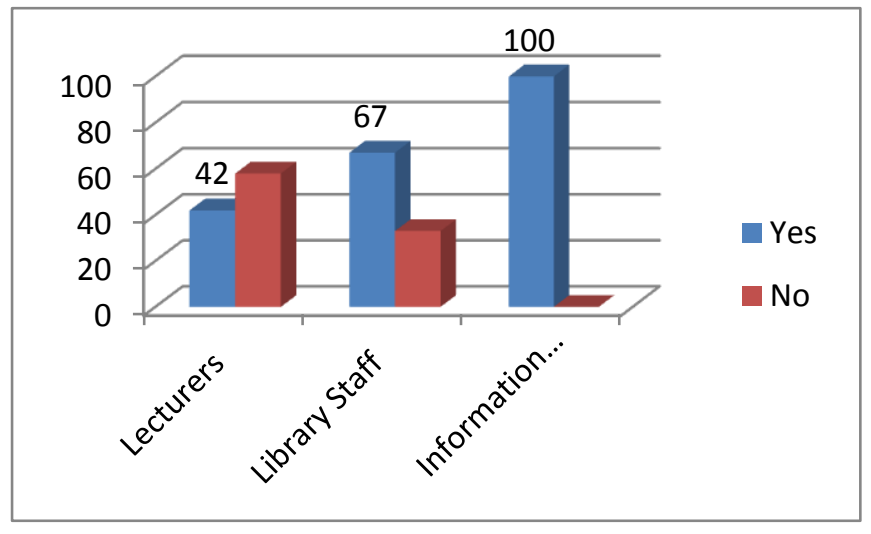

the findings revealed that $91(25 \%)$ BEDTTs rated conversance with phrase searching, as excellent, 120(33\%) BEDTTs rated conversance with phrase searching, as good, 69(19\%) BEDTTs rated conversance with phrase searching technique,

Figure 2 Staff teaching bachelor education trainees searching techniques

The finding affirmed that out of the 19(100\%) lecturers involved, $8(42 \%)$ lecturers teach BEDTTs information searching techniques, whereas $11(58 \%)$ do not. Additionally, findings revealed that $4(67 \%)$ library staff teach BEDTTs information searching techniques, while 2(33\%) library staff do not. More still, findings indicated 2(100\%) ISLs teach BEDTTs searching techniques. The findings confirmed that $2(100 \%)$ ISLs, $8(42 \%)$ lecturers and 4(67\%) library staff promote utilization of e-resources by BEDTTs. Furthermore, the findings revealed that 11(58\%) lecturers and 2(33\%) library staff do not promote utilization of the resources by not teaching BEDTTs searching techniques. The findings do not conform to the outcome of research conducted by Lwoga (2014) which acknowledged the importance of exposing undergraduates to information searching techniques. The reason for the non-conformity is because $11(58 \%)$ lecturer and $2(33 \%)$ library staff do not teach BEDTTs searching techniques. The implication is that BEDTTs experience challenges of searching the right information with ease.

\section{Information skills librarians' rate of teaching searching techniques}

This study sought to establish the frequency of teaching BEDTTs specific searching techniques. The ISLs were asked to indicate the frequency of teaching BEDTTs searching techniques. The findings are presented in Table 2.

Table 2: Information skills librarian's rate of teaching searching techniques

\begin{tabular}{|c|c|c|c|c|c|c|c|c|}
\hline Searching Techniques & \multicolumn{2}{|c|}{ Never } & \multicolumn{2}{|c|}{ Rarely } & \multicolumn{2}{|c|}{ Often } & \multicolumn{2}{|c|}{ Very often } \\
\hline & $\mathbf{F}$ & $\%$ & $\mathbf{F}$ & $\%$ & $\mathbf{F}$ & $\%$ & $\mathbf{F}$ & $\%$ \\
\hline Frequency of teaching keyword searching & 0 & 0 & 0 & 0 & 2 & 100 & 0 & 0 \\
\hline Frequency of teaching Boolean searching & 0 & 0 & 0 & 0 & 2 & 100 & 0 & 0 \\
\hline Frequency of teaching truncation technique & 0 & 0 & 0 & 0 & 2 & 100 & 0 & 0 \\
\hline Frequency of teaching wildcard technique & 0 & 0 & 1 & 50 & 1 & 50 & 0 & 0 \\
\hline Frequency of teaching phrase teaching & 0 & 0 & 0 & 0 & 1 & 50 & 1 & 50 \\
\hline
\end{tabular}

According to the findings, 2(100\%) ISLs teach BEDTTs keyword searching technique, often, 2(100\%) ISLs teach Boolean searching technique, often, while 2(100\%) ISLs teach truncation searching technique, often. Furthermore, 1(50\%)
ISLs teach BEDTTs phrase searching technique, very often, whereas $1(50 \%)$ teach BEDTTs phrase searching technique, often. Additionally, the findings revealed that 1(50\%) ISLs teach wildcard searching technique often, whereas $1(50 \%)$ 
rarely, teach wildcard searching technique. The findings indicated that the most taught online searching technique by ISLs is phrase searching technique, followed by the Boolean logic, keyword and truncation. However, the finding affirmed that the least taught online searching technique is wildcard searching technique, because $1(50 \%)$ ISLs rarely teach BEDTTs the technique. This implied that BEDTTs experience challenges when formulating search strategies using wildcard technique.

\section{Library staff rate of teaching pre-service teachers searching skills}

The study sought to find out the frequency of library staff's teaching BEDTTs searching techniques. The library staff were asked to rate the frequency of teaching BEDTTs keyword, phrase, wildcard, truncation and Boolean operator searching techniques. The findings are presented in Table 3.

Table 3: Library staff's rate of teaching bachelor of education trainee's searching

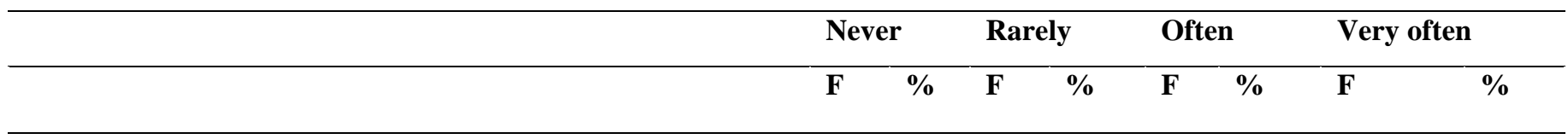

\begin{abstract}
Frequency in key word searching
Frequency in Boolean searching

Frequency in truncation technique

Frequency in wildcard technique

Frequency in phrase searching
\end{abstract}

$\begin{array}{llllllll}0 & 0 & 0 & 0 & 6 & 100 & 0 & 0 \\ 0 & 0 & 2 & 33 & 4 & 67 & 0 & 0 \\ 0 & 0 & 4 & 67 & 2 & 33 & 0 & 0 \\ 0 & 0 & 5 & 83 & 1 & 17 & 0 & 0 \\ 0 & 0 & 2 & 33 & 3 & 50 & 1 & 17\end{array}$

The findings indicated that $6(100 \%)$ library staff often teach BEDTTs keyword searching. More still, findings revealed that $4(67 \%)$ library staff often teach

BEDTTs the Boolean techniques, whereas 2(33\%) library staff rarely teach the Boolean operator techniques. Furthermore, the findings indicated that $1(17 \%)$ library staff teach BEDTTs phrase searching technique very often, while 3(50\%) library staff teach BEDTTs phrase searching techniques often. Additionally, 2(33\%) library staff rarely teaches BEDTTs phrase searching. Nonetheless, the findings indicated that $2(33 \%)$ library staff teaches truncation searching technique often, while $4(67 \%)$ library staff rarely teach BEDTTs truncation searching technique. Furthermore, the findings indicated that $1(17 \%)$ library staff teaches BEDTTs the wildcard searching technique often, whereas $5(83 \%)$ librarians rarely teach BEDTTs the wildcard searching technique. The findings affirmed that the most taught searching technique is keyword searching technique where $6(100 \%)$ library staff often teach the skills, followed by phrase, Boolean logic and truncation, in that order. However wildcard is the least taught searching technique because $5(87 \%)$ library staff rarely teach the technique. The implications of the findings were that BEDTTs were not be conversant with truncation and wildcard techniques and this impede utilization of e-resources. This implied that the BEDTTs waist time searching information using wildcard technique. The findings do not agree with Toyo (2017) findings which confirmed that undergraduates utilized e-resources due to conversance with a wide range of searching techniques.

\section{Conclusions}

The objective of the study was to establish the relationship between BEDTTs' searching ability and utilization of eresources. The study established that there was a statistical association between BEDTTs' information searching and utilization of e-resources $(\mathrm{p}<0.05)$. The findings indicated that improving BEDTTs information searching ability increases utilization of e-resources by the learners.

The findings have established that the University of Nairobi has availed different types of e-resources to be utilized by preservice teachers (BEDTTs) to advance academic work. The study also established that information literate abilities have a relationship with utilization of e-resources. The study made several conclusions. The study concluded that there was a significant statistical association between information searching and utilization of e-resources $(p<0.05)$. It follows that any improvement on BEDTTs' information searching increases utilization of e-resources.

\section{Recommendations}

The study recommend the university to offer guidelines to information skills lecturers, library staff and lecturers on current practices of supporting pre-service teachers to utilize e-resources. All the subject lecturers, ISLs and library staff should teach BEDTTs information searching techniques like keyword, phrase, Boolean operator, truncation and wildcard techniques. This would enable the BEDTTs' to utilize eresources to prepare class notes or complete assignments. The study recommend that a clause on teaching of IL be included in the UoN Library's mission statement. This will inform the BEDTTs that acquiring IL abilities is an institution-wide goal which every learner must achieve. More still, a policy to guide practical hands-on sessions on e-resources should be implemented to improve BEDTTs' searching ability. Furthermore, a policy compelling universities to acquire adequate computers and installation of stable internet facilities should be implemented to enhance utilization of e-resources by BEDTTs without interruptions. Moreover, the study 
recommend further research on "BEDTTs' utilization of eresources" and enrich the body of knowledge on searching ability and utilization of e-resources. More, still, a similar study should be carried out in private universities in Kenya. Furthermore, a comparative study should be carried out comparing utilization of e-resources in well-established universities and newly established universities.

\section{References}

[1] Adeniran, P. (2013). Usage of electronic resources by undergraduates at the Redeemer's

[2] University, Nigeria. International Journal of Library and Information Science, 5, pp. 319-324

[3] Association of College and Research Libraries (ACRL). (2016). Framework for information literacy for higher education. Retrieved on $20^{\text {th }}$ January 2016. From: www.ala.orf/acrl/standards/ilframework

[4] Driscoll, M. P. (1994). Psychology of learning for instruction. Boston: Allyn and Bacon.

[5] Burba, J. (2013). Gagnes' theory of instruction: A learning theory. Retrieved $12^{\text {th }}$

[6] February 2017 http://julietausend.com/2013/05/06/gagnes-theory-ofinstruction-a-learning-theory/

[7] Dhanavandan, S., Esmail, $M$ and Nagaranjan (2012). Use of electronic resources at Krishnasamy College of Engineering and Technology Library, Cuddalore. Library

[8] Philosophy and Practice. Retrieved $23^{\text {rd }}$ June 2016. From: http:// www.unllib.uni.edu/LPPpdf

[9] Duke, S and Ward, D. (2009). Preparing information literate teachers: A metasynthesis.

[10]Library and Information Science Research, 31 pp.247256.Retrieved $12^{\text {th }} \quad$ July $2016 \quad$ From: http://dx.doi.org/10.1016/jlisr.2009.04.003

[11] EBSCOHost. (2017). EBSCO interfaces user guides using wildcards and truncations.

[12] Accessed on $12^{\text {th }}$ May 2017. From: https://help.ebsco.com/interfaces/EBSCO_Guides/EBSC O_Interfaces_User_Guides/Using_Wildcards_and_Trunc ation

[13] Ekenna, M. and Igabo, M. (2013). Information retrieval skills and use of library electronic resources by university undergraduates in Nigeria. Information and

[14] Knowledge Management, 3, pp. 6-15. Retrieved $16^{\text {th }}$ January 2017 from: https://de.slideshare.net

[15] Fallon, H. and Breen, E. (2012).The changing role of the academic library in learning and teaching: Emerging Issues. National Academy for Integration of Research, Teaching and Learning, University, 2, pp. 141-152 Gagne, R., Briggs, L. and Wager, W. (1992). Principles of instructional design.

[16] Fort Worth: Harcourt Brace Jovanovich.

[17] Fister, B. (2013). Decode Academy Lecture Presented at the Annual LOEX Conference,

[18] Nashville, Tennessee, May 32013.
[19] Haridasan, S and Khan, M. (2009). Impact of e-resources by social scientists in National Science Documentation Centre (NASSDOC), India. The Electronic Library, 27, pp.117-133 Kayvan, K., Kamran, S and Sauid, I. (2011). How to use Gagne's model of instructional design in teaching psychomotor skills. Gastroenterol Hepatol Bed Bench. 4, pp.116-119

[20] Khan, J. (2016). Awareness and use of digital resources and services in the IIT Delhi Library. International Journal of Research-GRANTHAALAYAN, 4.

[21] Kovalik, C., Jensen, M., Schloman, B. and Tipton, M. (2010) "Information Literacy,

[22] Collaboration, and Teacher Education. Communications in Information Literacy 4, pp. 145-69. Retrieved on $13^{\text {th }}$ July $2016 . \quad$ From: http://www.comminfolit.org/index.php?journal=cil\&page $=$ article $\&$ op=view $\&$ path

[23] Lwoga, E. (2014). Mapping information literacy outcomes and learning experiences of health sciences undergraduate students. Partnership: The Canadian Journal of Library and Information Practice and Research, 9, pp. 2-17.

[24] Mardhusudhan, M. (2010). Use of electronic resources by research scholars of Kurukshetra University. The Electronic Library, 28, pp. 492-506.

[25]Medical Library Africa. (2017). Module three: Electronic information searching techniques. Retrieved on $4^{\text {th }}$ August 2017.2 From: http://karibouconnections.net/medlibafrica/trainingmodule/pdf

[26] Mwantimwa, K and Elia, E. (2017). Utilisation of EResources to Support Teaching and Research in Higher Learning Institutions, Tanzania. University of Dar es Salaam Library Journal, 12, pp-98-123 Nyamboga, C. (2014). E-resources complexities and their use among Information Science students Mount Kenya University, Kigali Campus. Global Journal Engineering Science and Research Management, 1, pp.14-23

[27] Okello-Obura, C. and Magara, E. (2008). Electronic Information access and utilization by Makerere University students in Uganda. Retrieved on $23^{\text {rd }}$ February2017 From: http://creative commons.org/licenses/by/2-0.

[28] Omosekejimi, A., Eghworo, O. and Ogo, E. (2015). Use of electronic information Resources (EIRS) by undergraduate students of Federal University of Petroleum resources, Effurun. Information and Knowledge Management, 5, 94-103

[29] Oparah, O and Faloye, J. (2011). Beyond the lesson plan: an eye of the teachers' emotion [IN Ogundele, O., Moronkola, O and Babalola, J (Eds.). Contemporary issues education, health and sports: the way forward.] Ibadan: University of Ibadan.

[30] Porter, B. (2011). Millennial Undergraduate Research Strategies in Web and Library Information Retrieval Systems. Journal of Web Librarianship, 5, pp. 267-285 
[31] Schugar, R., Smith, A, and Schugar, T. (2013).Teaching with interactive picture E-books in grades K- 6. Reading Teacher, 66, pp. 615-624.

[32] Shittu, A., Kareem, B., Obielodan, O. and Fakomogbon, M. (2017). Investigating predictors of pre-service science teachers' behavioral intention toward e-resources for teaching. Contemporary Educational Technology, 8, pp. $142-157$

[33] Sithole, N., Chisita, C. and Jagero, N. (2015). Information literacy evaluation: A case of the Africa University, Mutate, Zimbabwe. British Journal of Education, Society and Behavioural Science.9, pp. 341-151

[34] Starret, R. (1994). CD-ROM fundamentals. Massachusetts: Boyd \& Thompson Publishing.

[35] Southeastern Louisiana University (2010). LS 102: Introduction to Information Research (http://www3.selu.edu/adunnington/LS102/)

[36] Toyo, D., (2017). Undergraduate's information literacy skills and the use of electronic resources in Delta State University, Abraka, Nigeria. International Journal of Education and Evaluation, 3, pp. 27-36

[37] Ukachi, N., (2015), Information literacy of students as a correlate of their use of electronic resources in university libraries in Nigeria. The Electronic Library, 33,pp. 486501

[38] Umunnakwe, G and Eze, J. (2015).Information needs and resources provision for secondary school teachers in Imo State, Nigeria: Male versus female teachers Library Philosophy and Practice. Retrieved on $12^{\text {th }}$ January 2018: From: http://digitalcommons.unl.edu/libphilprac/1242

[39] Yusuf, $M$ and Balogun, M.(2011). Student-teacher competence and attitude towards information and communication technology: A case study in a Nigerian university.

[40] Contemporary Educational Technology, 2, pp. 18-26. 